\title{
АНАЛИЗ БИБЛИОТЕКИ СОЕДИНЕНИЙ \\ С ПОТЕНЦИАЛЬНОЙ ПРОТИВООПУХОЛЕВОЙ АКТИВНОСТЬЮ С ПОСЛЕДУЮЩИМ ВЫДЕЛЕНИЕМ ИХ НАИБОЛЕЕ АКТИВНЫХ СТРУКТУРНЫХ КЛАСТЕРОВ
}

\author{
И.В. Жиркина', Д.А. Скворцов', Л.А. Васильева² \\ ${ }^{1}$ Химический факультет, Московский государственный университет имени \\ М.В. Ломоносова, 119991, Россия, Москва, Ленинские горы, д. 1, стр. 3. \\ 2Факультет биоинженерии и биоинформатики, Московский государственный университет \\ им. М.В. Ломоносова, 119991, Россия, Москва, Ленинские горы, д. 1, стр. 73.
}

DOI: 10.19163/MedChemRussia2021-2021-268

E-mail: irina.zhirkina@chemistry.msu.ru

По данным ВОЗ онкологические заболевания являются одной из основных причин смерти в мире. В связи с этим поиск низкомолекулярных соединений с потенциальной противоопухолевой активностью остаётся важно задачей для науки.

Ранее нами была разработана методика флуоресцентного скрининга с использованием двух моделей: рака лёгкого и рака молочной железы, в основе каждой из которых лежит сокультивация флуоресцентных клеточных линий опухолевого и неопухолевого происхождения. Эти модели были использованы для исследования селективной цитотоксичности порядка 10000 соединений, отобранных различными методами.

В ходе исследования был выделен ряд кластеров структур соединений, показавших наибольшую селективную цитотоксичность на вышеуказанных моделях. Среди таких кластеров: производные дигидро-6-метил2(1Н)-пиримидинтиона; производные хиназолинов, индолов и их конъюгаты; производные диазинетрионов. Для наиболее активных соединений внутри каждого кластера было проведено подтверждение данных скрининга с помощью независимого МТТ-теста. Более того, для каждого из кластеров но основании всех исследований и анализа литературы удалось построить зависимость структура-свойство. Данные результаты были использованы для отбора соединений в рамках следующего поколения скрининга и оптимизации их структурных свойств. 